\title{
Z-source DC- DC Converter for Low Power Application in Micro Grid Operation
}

\author{
Sangita H Deshmukh ${ }^{1}$, P V Kapoor ${ }^{2}$ and D. R. Tutakne ${ }^{3}$ \\ ${ }^{1,2}$ Assistant Professor, Shri Ramdeobaba College of Engineering and Management,Nagpur \\ ${ }^{3}$ Professor, Wainganga College of Engineering and Managment, Nagpur, India
}

\section{ABSTRACT}

Nowadays DC- DC converters are widely used in Microgrids for synchronization of distributed generators with AC and DC power lines and for low power applications. Therefore it becomes very necessary to improve the performance of AC-DC convertor The main emphasis is given on power factor improvement on supply side. To achieve this Z-source AC-DC power convertor is proposed in this project. By using Z-source at the input side transient response of convertor gets improved and power factor is obtained nearly equal to unity. Proposed scheme uses ferrite core high density, high frequency transformer. For the proposed scheme results are obtained by simulation and simulation results are validated with the hardware results.

KEY WORDS: HIGH FREQUENCY(HF), DC-DC PUSH-PULL CONVERTOR, HIGH DENSITY, MICRO GRIDS , DC TRANSFORMER.

\section{INTRODUCTION}

Nowadays Power electronic converters are widely used in many applications including renewable energy generation, microgrids synchronization ,Initially AC gains more advantage over DC . But now a days DC come back and is replacing AC. For the advantages of DC over AC the main focus is on it's technical advantages from microgrid point of view and it's cost. For proper analysis of DC versus AC two classical transformers i.e. $\mathrm{AC}$ transformer and DC transformers are compared. In case of DC fast switching power electronics provides improved performance and controllability which is very poor in case of AC transformers. Again the most

\section{ARTICLE INFORMATION}

*Corresponding Author: deshmukhsh@rknec.edu

Received 15th Oct 2020 Accepted after revision 24th Dec 2020

Print ISSN: 0974-6455 Online ISSN: 2321-4007 CODEN: BBRCBA

Thomson Reuters ISI Web of Science Clarivate Analytics USA and Crossref Indexed Journal

\section{1) Clarivate Crossef}

NAAS Journal Score 2020 (4.31)

A Society of Science and Nature Publication,

Bhopal India 2020. All rights reserved.

Online Contents Available at: http//www.bbrc.in/

Doi: http://dx.doi.org/10.21786/bbrc/13.14/24 serious issue regarding materials required for $\mathrm{AC}$ and DC transformers.

AC transformer requires $2.5 \mathrm{~kg}$ of copper or steel per $\mathrm{kW}$ capacity of grid whereas DC transformer requires 0.25 $\mathrm{kg}$ per $\mathrm{kW}$ capacity of grid. There are two types of DC transformers depending on single phase high frequency transformer which is applicable for low power applications at low voltage distribution level such as for battery charging applications, industrial equipment/motor drives, electric vehicle/train, aircraft, household appliances, computer power supplies, power for telecommunication equipment, etc The scheme is proposed for single phase high frequency, high density push-pull AC-DC convertor. Designers of DC-DC power converters are under relentless pressure to increase power density, efficiency, reliability, improves transient response, and reduce cost, preferably achieving all these goals simultaneously, therefore the most important requirement is that the introduction of DC -DC convertor should not introduce harmonics in the system. DC-DC and AC-DC convertors are used mostly to connect solar power to DC and AC microgrids. 
The most commonly used DC-DC convertors are pushpull amplifier, Buck-boost convertors, half bridge , full bridge convertors. In the scheme high frequency push-pull amplifier with z-source at supply side is proposed. With this power factor on input side gets improved and thus power quality gets improved which in turn will reduce the harmonics in microgrids.. This improves the power factor of the source, i.e. of input voltage and input current. Also by using variable duty ratio, variable output voltage is obtained to meet the load requirement. The simulation results for the proposed topology is found using MATLAB and PSIM software. The simulation results are validated with the results of the hardware model of the proposed HF push-pull DC transformer with z-source.

The hardware model for control circuit and power circuit is presented. In the near future the electrical grids based on DC will become more and more attractive and cost-effective than AC. To design a universal interface between DC sources and higher voltage systems and synchronism with microgrids is one of the challenging tasks. In proposed DC transformer with z-source both switching and conduction losses, can be reduced and consequently the overall efficiency can be improved. Another advantage of the proposed converter is its extremely low output current ripple which requires an additional small inductor. All these benefits are obtained without applying additional stress on active components or using transformers.

Research Methodology: HF DC transformer using PushPull Topology: Push-Pull topology is used because of its high power handling capability than a buck, boost and buck-boost converter. The control may be introduced at any stage, the actual stage depends on the load requirements and the overall cost structure. In order to improve the performance of conventional DC-DC push pull transformer it is designed with Z-source with soft switching [3] in the input side Figure 1(a) represents the circuit diagram of conventional push-pull DC-DC converter/transformer and figure (b) represents pushpull DC-DC converter with z-source. Figure 1 represents the conventional converter and proposed converter with z-source.

Figure 1: (a)Circuit Diagram of conventional Push-Pull DC-DC Converter (b) circuit diagram of push-pull converter with z-source

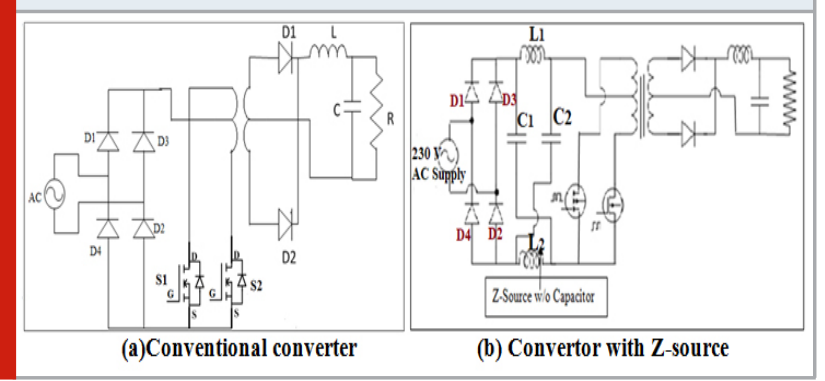

Performance Improvement of DC-DC Converter using z-source: A $z$-source converter is a unique $\mathrm{x}$-shaped impedance network called Z-source impedance network [1] Work in this thesis represents the study on its superiority compared to conventional converter. The operation principle of the proposed topology and comparison with the conventional topology is analyzed in detail with the help of simulation and then Simulation results are validated with the hardware experimental results to demonstrate the new features of the improved topology and it successfully worked. Figure2 represents simulation circuit of z-source push-pull DC transformer/ converter. Second diagram represents z-source output voltage without filter capacitor. Figure 3 represents complete hardware circuit which includes z-source push-pull convertor, high density and high frequency ferrite core transformer, driver circuit using IR2110 to boost the voltage from 3.92 volt to 8 volts and control circuit for generation $50 \mathrm{kHz}$ control pulses using microcontroller dsPIC33EP256MC202. Since proposed DC-DC transformer is a step down transformer, current on input side is very low and therefore $z$-source inductance required is very small and it is in milli henrys.

Figure 2: simulation circuit of z-source push-pull converter with expected voltage waveforms

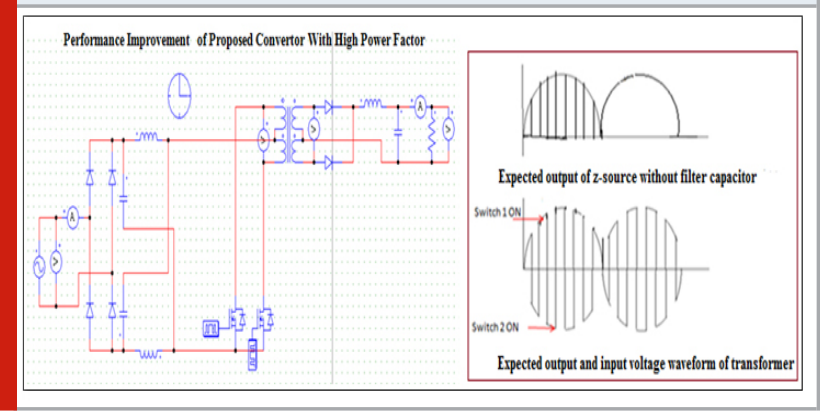

Figure 3: complete hardware set up of z-source push-pull DC-DC Convertor

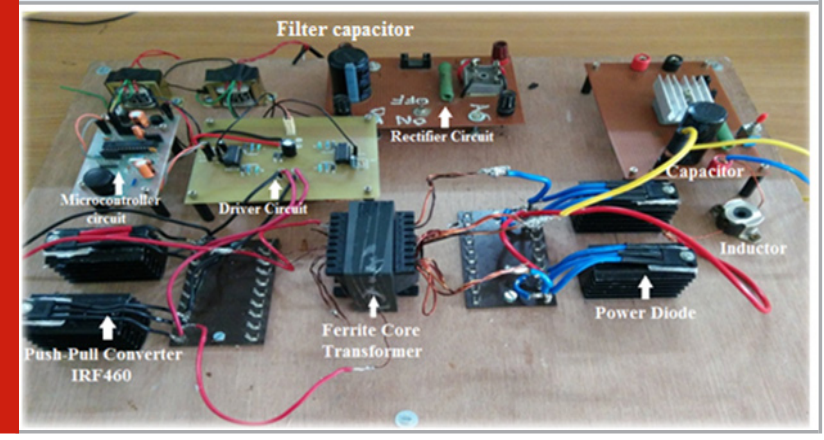

Validation of Simulation results with hardware: Figure 4 (a) represents hardware results of 3.92 volt, $50 \mathrm{kHz}$ switching frequency obtained from microconroller dsPIC33EP256MC202 and figure 4 (b)represents $50 \mathrm{kHz}$ pulses from simulation circuit. Figure 5(a) represents simulation results of line voltage and line current and figure 5(b) represents hardware results of line voltage 
and line current. It is seen that in both the cases line current is nearly in phase with the line voltage getting nearly unity power factor. Figure 6 represents Improved performance of the proposed converter using z-source showing high power factor on the supply side at 50 $\mathrm{kHz}$. Figure 6 represents high density transformer input and output voltage envelope with z-source. Red color is input voltage and blue color represents output voltage envelope. This result is obtained due to shifting of capacitor from input side of rectifier to the output side of converter.

Figure 7 represents DC voltage and DC current across load of proposed converter with z-source at $50 \mathrm{kHz}$ switching frequency. Figure 7 (a) is simulation result which is obtained for $1 \mathrm{ohm}$ load resistor which gives $24 \mathrm{~A}$. and figure 7 (b) represents hardware result which shows 13 A load current and $22 \mathrm{~V}$ across DC load. Figure 8(a) represents transient response of DC voltage and current across load without $\mathrm{z}$-source and figure $8(\mathrm{~b})$ represents transient response with z-source both at $50 \mathrm{kHz}$. Figure 9(a) represents improved performance of the proposed con verter using z-source showing high power factor on the supply side at $50 \mathrm{kHz}$ and figure $9(\mathrm{~b})$ represents performance without z-source resulting in spikes in supply current which results in harmonics.

Figure 4: 3.92 volt, $50 \mathrm{kHz}$ switching frequency PWM pulses From microcontroller dsPIC33EP256MC202.

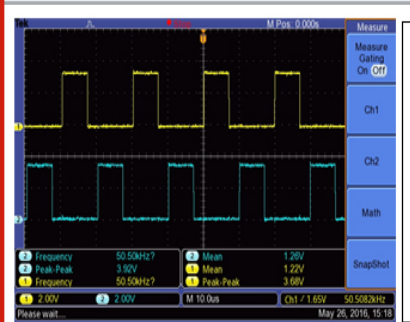

(a) hardware result

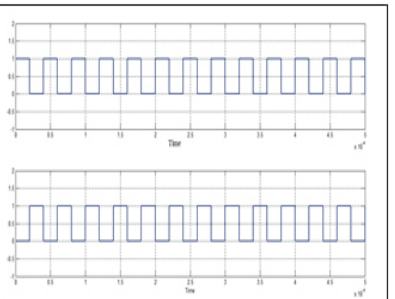

(b) simulation result
Figure 5 : (a) Line voltage and line current with high power factor at $50 \mathrm{KHz}$ frequency.

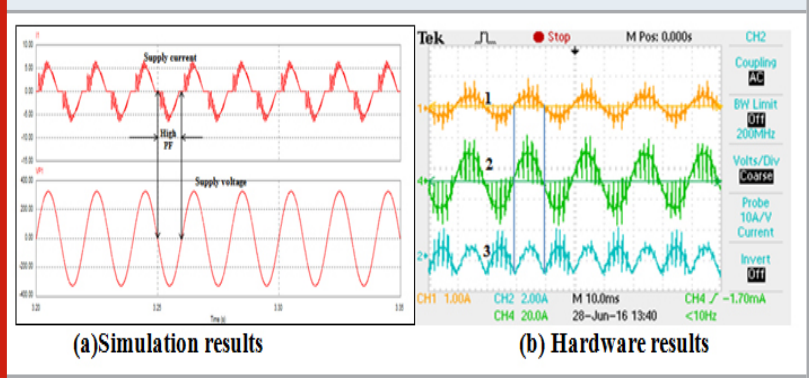

\section{RESULT AND CONCLUSION}

Thus it is prooved from the simulation and experimental results that newely developed high frequency high density $50 \mathrm{kHz}$ DC-DC push-pull transformer results in high power factor almost unity and also the improved transient response and thus can improve the performance in microgdid for low power applications. Improvement in
Figure 6: High density transformer input and output voltage with z-source

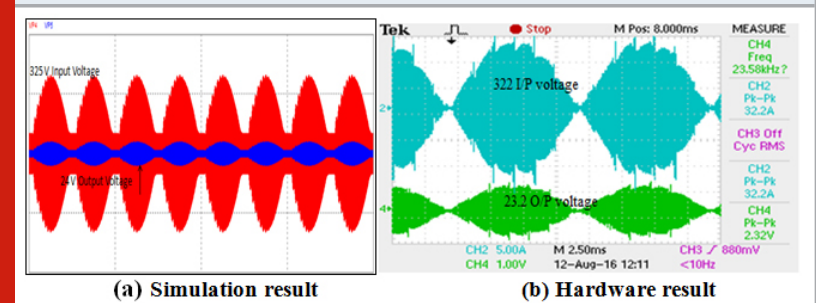

(a) Simulation result

(b) Hardware result

Figure 7: Output voltage and current of DC transformer with z-sourse

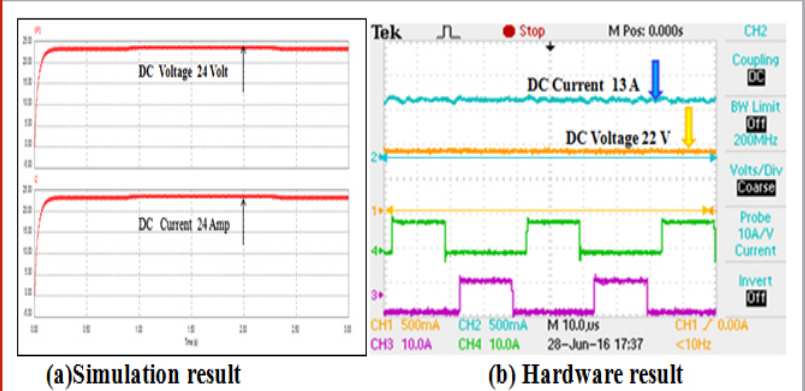

Figure 8: DC current and DC voltage waveform across load indicating transient response at start

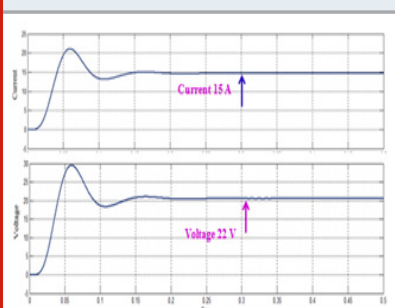

(a)Transient response w/0 Z-source

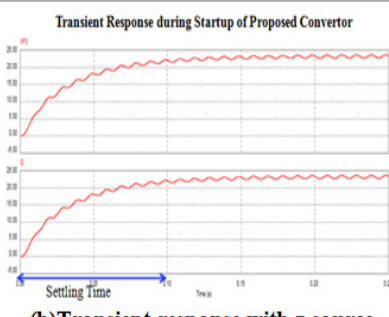

(b)Transient response with Z-source
Figure 9: Performance of the converter on the supply side at $50 \mathrm{kHz}$

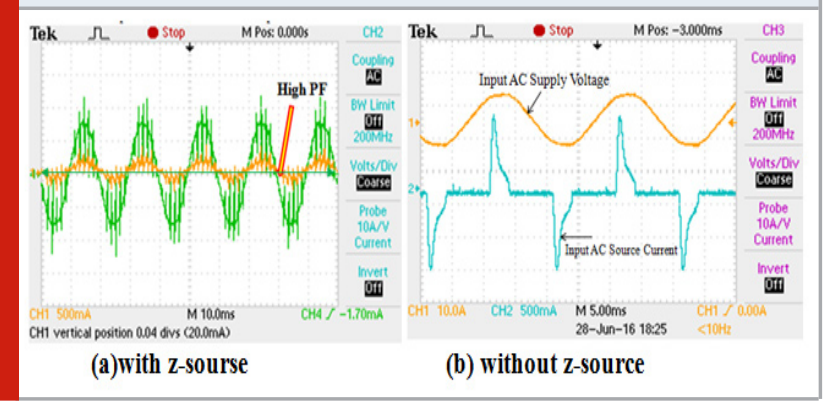

power factor is the most important feature achieved of this DC transformer which will help in reducing the the harmonics in microgrids. For $50 \%$ duty ratio at $50 \mathrm{kHz}$ switching frequency shoot through of the switches is taken care by z-source. In this push-pull DC transformer start up current transient response time has reduced considerably. 


\section{REFERENCES}

S. H. Deshmukh, M. Giri, V. T. Barhate and D. R. Tutakne 2017, "Z-source high frequency AC/DC pushpull converter with high input power factor," 2017 International Conference on Energy, Communication, Data Analytics and Soft Computing (ICECDS), Chennai, , pp. 3206-3210, doi: 10.1109/ICECDS.2017.8390048.
S. Devikala P.Nirmalkumar, "Experimental Verification of Soft Switching Push-Pull DC to DC Converter", International Conference on Power Electronics, Drives and Energy Systems December16-19, 2012.

Z. Kaczmarczyk and W. Jurczak, "A pushpull class-e inverter with improved efficiency," Industrial Electronics, IEEE Transactions on, vol. 55, pp. 18711874, April 2008. 